\title{
Digitalisation and the Foundational Economy: a digital opportunity or a digital divide for less-developed regions?
}

\author{
Laura Reynolds, Dylan Henderson (Cardiff Business School), Chen Xu (Swansea \\ University, Economics), Laura Norris (Cardiff University, Geography and Planning)
}

Accepted for publication in Local Economy journal, 17 $7^{\text {th }}$ December 2021

Part funded by the European Regional Development Fund and Welsh Government

\section{Introduction}

The foundational economy (FE) comprises the prosaic products and services that are "necessary for everyday life" (Leaver and Williams, 2014: 220). Consumed irrespective of wealth or locality, these everyday businesses are receiving academic and policy interest, with heightened support being premised as a route towards more inclusive and sustainable economic development models. Spatially, the FE is characterised by its dispersal across all parts of a region, with services linked to "physical infrastructures or the need for human-to-human interaction" (Hansen, 2021: 4). In this respect, the local and embedded components of these businesses provide a mechanism in which to support and ground local economies (De Boeck et al., 2019; Thompson et al., 2020). Here, proponents of the FE have highlighted its potential in less-developed regions, lacking in high growth and productive businesses, to contribute towards regional development (Morgan, 2019). Of particular interest to this paper is the embedded nature of foundational businesses and their potential to stabilise less-developed regional economies. These businesses are rooted in local supply and planning networks and have developed relationships based on trust and sharing of tacit knowledge (De Boeck et al., 2019; Engelen et al., 2017). This holds the prospect for the FE to benefit less-developed regions, and to redress some of the weaknesses of past policy prescriptions that have tended to focus on securing inward investment to support high technology at the expense of the FE (Morgan, 2019). The emerging policy response that places FE at the forefront of regional development remains in its early stages (Barbera and Jones, 2020). More 
research is needed to understand the capacity of the FE to capture these potential policy gains.

In this paper, we address the underexplored impact of digitalisation on the FE (Hansen, 2021), asking to what extent digital adoption and capability may enable or impede the FE as a place-based policy initiative capable of reducing the social and economic challenges faced by less-developed regions. We do so by developing an indepth case study of the digitalisation of the FE in Wales. Using mixed methods, we undertake regression analysis of survey data of small-to-medium enterprises (SMEs) to examine whether a digital divide between foundational and non-foundational businesses exists, looking also for differences based on geography and within the FE. Second, using in-depth interviews with foundational SMEs we examine the processes that impede digital capability and whether they are also capable of having spatial and structural implications. Together, we contribute to the emerging regional development literature on the FE by demonstrating digital differences both within foundational businesses and across geographical space. By drawing on embeddedness, our theoretical contribution lies in examining how spatial embeddedness and digital (dis)embeddedness interact and influence the pursuit of sustainable and inclusive growth models.

\section{Defining the foundational economy}

The FE, oft-cited as the everyday economy, provides the goods and services sufficient for day-to-day living (Estela, 2019). Three categories are identified, namely (a) the providential, (b) material, and (c) overlooked (FE Collective, 2020). In turn these are considered as society's primary resources (health, care, education), the tools that allow citizens and societies to function (roads, cables, broadband, banking, food production), and the culturally-defined necessities purchased regularly for everyday living (retail, hospitality, tourism). Increasing attention has been paid to the first two categories, examining the pivotal role of infrastructure construction, and public sector health and social care (De Boeck et al., 2019). While all categories are important, we suggest that overlooked foundational businesses receive a paucity of academic attention.

Central for this paper, the FE is not spatially nor structurally differentiated, and provides a potential source of stability and shelter for regions (Pike et al., 2017; Thompson et al., 2020). Foundational organisations also encompass a mixture of public, 
private and third sector actors (De Boeck et al., 2019) and provide necessities for all irrespective of location, class or income (Engelen et al., 2017). While increases in public sector spending can support the everyday infrastructure, including high speed broadband, there is also a need to examine businesses, the large proportion being micro or small enterprises (Henley and Lang, 2017). This article addresses these FE characteristics, assessing how public sector spending on broadband infrastructure can support foundational businesses across the material, providential and overlooked categories.

\section{Foundational economy, stability and inclusive growth}

Conventional approaches to local and regional economic development previously omitted the hidden foundational activities (Hansen, 2021; Morgan, 2020). More recently, the FE is becoming an area of interest, as a route towards assisting less-developed regions where the economic and institutional context may be less supportive of regional development (Pike et al., 2017). Studies recommend promoting economic development through entrepreneurship, innovation and investment (Birch et al., 2010; Coenen et al., 2015). It has been found, however, that less-developed regions face particular challenges due to a lack of high growth sectors and sources of new knowledge (Coenen et al., 2015), a decline of established 'old' industries (Trippl and Otto, 2009) and a peripherality to main centres of economic activity (Mason et al., 2015). The FE, in its close links to the everyday functioning of the local economy (Estela, 2019) may provide an alternative focus for place-based policies (De Boeck et al., 2019; Hassink, 2020; Morgan, 2019).

While the FE has been identified as potential source of stability for less-developed regions, there is a danger that policy development may run in advance of understanding foundational sectors and their role in regional economies. Early policy efforts have focused on the concept of experimentalism (Barbera and Rees Jones, 2020). Such an approach highlights the need for policy solutions to be locally developed and place sensitive. It suggests that 'off the shelf' policy solutions are unlikely to respect the sectors' grounded nature, and proposes experimental learning amongst stakeholders is best placed to develop its sectors. The argument developed in this paper is that alongside such efforts the public sector has agency to support the FE as a whole through its efforts to deploy and encourage the use of digital technologies. That is, while the support for foundational sectors may help less-developed regions to reduce regional disparities and 
produce socio-economic impacts for rural regions (Pike et al., 2017), more is needed to understand the FE and develop policy that supports these institutional and governance shifts (Nygaard and Hansen, 2020; Pike et al., 2017).

Inclusive growth has emerged as a 'buzz word' to describe the strategies that have challenged existing agglomeration-based models and reorientated towards socioeconomic aims (Deas et al., 2020; Lee and Sissons, 2018). Despite being critiqued for conflating competing economic development ambitions (Lee, 2019), the underpinnings of the concept as a route to concurrently redistribute wealth and stimulate growth are gaining traction in discursive and policy channels (Barzotto et al., 2020; Green et al., 2021). Even though imprecise, the concept appeals to policy makers who can adopt principles enabling more progressive goals (Deas et al., 2020). A heightened FE focus stems from these changing policy orientations, with emphasis shifting towards supporting local and grounded public, private and civic society organisations that can provide social as well as economic outcomes for economies.

These developments align with the heightened attention on the socio-economic benefits of the FE's embeddedness (Barzotto et al., 2020; Thompson et al., 2020). Thompson et al. (2020) draw on Polanyian understanding of the economy and embeddedness (Polanyi, 1944 cited in Thompson et al., 2020), which is critical of neoliberalism's support for market exchange at the expense of social wellbeing. The authors draw parallels between these views and recent interest in the FE and inclusive growth. Instead of focusing on productivity, FE support is aligned to the sectors' ability to provide stability (Froud et al., 2020; Engelen et al., 2017) and "controllable and locally embedded accelerators of growth" (Thompson et al., 2020: 1177). Polanyian moral economics has been influential in embeddedness theory, aligned to both network and normative embeddedness (Wood et al., 2019). The former "takes place through the generation of interpersonal trust networks built through micro-level interactions (Wood et al., 2019: 934), the latter refers back to critiques of market exchange focusing on the macro-level interactions and the ongoing commodification of labour, land and money. While network embeddedness holds longstanding recognition in economics literature (White, 2004), a focus on the FE as a step away from commodification requires consideration for both iterations of embeddedness.

\section{Spatial differences in digital infrastructure and digital uptake}


Although the FE has been identified as non-spatially exclusive (Morgan, 2020), the growing moves towards digital technology use may present socio-spatial opportunities and challenges (Hansen, 2021; Tranos and Nijkamp, 2013). While the digitalisation of essential providential and material services (e.g. social care, education, transport) may help users of these services across all regions, there are concerns that urban areas will disproportionately benefit from the regional economic returns coming from the production and delivery of digitalised FE services (Hansen, 2021). Moreover, regional inequalities in digitalisation are already well-established, with the deployment of digital technologies favouring urban areas with high subscriber bases, and higher concentrations of business (Grubesic and Mack, 2016; Tranos and Gillespie, 2009). These developments in digital infrastructure provide opportunities, but also potential challenges for FE services in less developed regions, Hansen (2021), for example, views digitalisation as providing the prospect for FE service access improvements in the quality and availability of providential (e.g. maintaining and improving services in a region, that may have otherwise been lost) and material services (e.g. provision of self driving buses), but raises the prospect of such services being delivered from urban areas, resulting in greater regional inequalities.

The wider literature on digitalisation has pointed to the role of digital technologies in supporting the emergence of new forms of economic activity such as digital platforms (Bearson et al., 2021; Kenney and Zysman, 2016). While offering some opportunities for 'elite' work in developing and managing platform technologies, platform models of business have also produced far less generous incomes and benefits, and bargaining positions for other workers (Bearson et al., 2021), and the potential for this to "drain the left-behind areas of resources" (Feldman et al., 2021: 43). These developments potentially present challenges to the FE, where ownership of digital technology assets is diminished (Brill et al., 2015). Digital platforms may, however, also offer opportunities for foundational sectors to provide localised shelter from these globalised developments, through cooperative models in sectors such as urban mobility and welfare services may offer opportunities for socio-economic value to be retained in less developed regions (Arcidiacono and Pais, 2020).

Research on digitalisation and the regional economy has also examined how there may be potential for such technologies to reenergise existing industry sectors. The 
concept of industry 4.0, for example, has highlighted the growing opportunities for digital advancements to support new production processes, through the introduction of technologies such as 3D printing, robotics and sensors (Bailey and De Propris, 2019). While such research has tended to focus on sectors traditionally prioritised by public policy, such advanced manufacturing sectors (Bentham et al., 2013), others have pointed to industry 4.0 in supporting foundational sectors such as food production and agriculture (Barzotto et al., 2020). The focus on adopting digital technologies in such sectors can, however, present challenges in less developed regions, where skills and capabilities to absorb and make use of such technologies may be limited.

The potential impact of digital technologies on the FE in less developed regions is therefore an open question (Hansen, 2021). In making use of digital technologies the FE may be able to support and sustain social and economic outcomes. Conversely, differences in access and use of digital technologies may extend existing spatial inequalities. This paper also recommends that the defining features of the FE need to be at the forefront of an investigation into the opportunities and challenges surrounding digitalisation, in particular the local and embedded nature of FE sectors within their local economies. As such, to investigate what digitalisation means for the FE and its ability to succeed as a place-based policy capable of encouraging inclusive growth in a lagging region, it is first important to examine the adoption and capability of the FE to implement digital developments and how any differences may assist or impede these policy initiatives.

\section{Methodology}

This paper uses a mixed methods case study of Wales' foundational SMEs to investigate if digital capability presents an opportunity or a barrier for foundational businesses and their local economies. We examine digital capability in relation to key factors that have been identified in the literature: digital skills, digital tools and infrastructure use, and digital supply chain relationships (Grubisec and Mack, 2016). In particular, examining the extent that a digital divide in these capabilities is present and the antecedents for these sectoral and ultimately spatial barriers.

Wales is well-documented in policy and academic discourse as a 'lagging region', with the European Union Cohesion Policy prioritising structural funds to help reduce 
regional inequalities (Jones et al., 2020). The lack of relative change has led policy makers to adopt a number of regional spatial justice initiatives to help alleviate regional disparities. The Welsh Government pioneered FE support through its 'Prosperity for All Economic Action Plan', providing a valuable context in which to research local and economic shifts (Thompson et al., 2020). The FE and inclusive growth initiatives hold legislative backing under the Wellbeing of Future Generations (Wales) Act 2015, which instructs policy to tackle regional inequalities, promote fair work, and provide appropriate infrastructure. Moreover, foundational businesses are central for the Welsh economy, with approximately 50 percent of Welsh employment deriving from foundational sectors (Pugh et al., 2018) and as much as 30 percent of household expenditure (Johal et al., 2017).

The case study provides scope to develop theoretical understandings of regional divides in a digital era. Welsh Government endorse digital solutions to foundational challenges, providing financial provisions for businesses able to implement digital and innovative solutions to modern problems (Institute of Welsh Affairs, 2020). Moreover, recent research has pointed to the regional economic development impacts stemming from the adoption of broadband enabled digital technologies across Wales in contributin towards employment and turnover effects (Henderson et al., 2020). Despite the recognition, there remains a need to empirical examine the FE digital-divide and its potential implications for regional policy.

\section{Stage 1}

This study draws on data collected through the 2017 and 2018 [redacted for anonymity] Survey (Author X - redacted). The survey was sent to a database of 260,000 Welsh SMEs. Central to the sample reliability was ensuring the survey returns were robust and representative. To do so, the returned surveys were checked against industry, business size and local authority locations. Where required, telephone interviews supported survey response rates, specifically for underrepresented industries and regions. Across the twoyear period 932 businesses completed the survey (Table 1).

[Insert Table 1] 
Our survey asked SMEs to record their business activity in line with the Office for National Statistics A21 Industry classifications and aligned NACE Rev.2 classifications (cf. Eurostat, 2008). While this provided less granularity, it was consistent with the participants' standard industrial classification (SIC) specific knowledge and time allocation. Further detail may have reduced reliability in self-reporting and the response rate. We aligned these activities with the 5-digit SIC -2007 set out by FE Collective (2020) to create a proxy of foundational classifications. Analysis was undertaken based on the businesses' foundational (across the three foundational categories) and nonfoundational status.

The survey instrument collects data on how businesses adopted 40 ICT items, based around five digital maturity dimensions. These dimensions are (1) ICT infrastructure, (2) ICT investment, (3) ICT capabilities, (4) digital use, and (5) ecommerce (see Appendix 1 in supplementary material). From these proxy variables a Digital Maturity Index (DMI) is created, helping to compare businesses' digital maturity.

A regression model was established to test the cross-sectional data and determine how firm characteristics affect DMI, how firms being foundational interacts with other key characteristics to affect firms' DMI, how DMI differentiates across being foundational and non-foundational businesses, and across different categories of foundational businesses. Our model is as follows:

$$
\begin{gathered}
\text { DMI }_{\text {it }}=\beta_{1} \text { Foundation }_{\text {it }}+\beta_{2} \text { Urban }_{\text {it }}+\beta_{3} \text { Size }_{i t}+\beta_{4} \text { Subregion }_{\text {it }}+\beta_{5} \text { Urban }_{i t} \\
* \text { Foundation }_{i t}+\beta_{6} \text { Year }_{i} * \text { Foundation }_{i t}+\beta_{7} \text { Year }_{i}+\varepsilon_{i t}
\end{gathered}
$$

This model is built on the following calculations. The foundation is a dummy variable that shows whether the business belongs to the FE (Regression Set 2), or which category of the FE (Regression Set 1). Urban, Size and Subregion are the categorical variables that show businesses' characteristics. Year shows the year fixed effect, whether the data is collected in 2017 or 2018. The rest 2 are interaction terms between foundational and Year or Urban. Age was also a control variable and its interactions with variable foundational were both included and not significant almost on all occasions, and therefore not included here. Variance Inflation Factor (VIF) is calculated to inspect for multicollinearity, with no serious multicollinearity detected in the model. 
Summary statistics were also used to examine the differences in the average digital maturity across the FE categories. This totalled frequencies of $n=279$ for nonfoundational and $n=515$ for foundational businesses. Broken down across the FE, the sample comprises of $7.56 \%(n=60)$ providential, $11.46 \%(n=91)$ material and $45.84 \%$ $(n=364)$ overlooked. While the overlooked forms $70.68 \%$ of the foundational businesses sampled, this reflects the broader industry categorisation for these culturally defined necessities, as well as their heightened propensity in the Welsh economy.

\section{Stage 2}

Stage 2 utilised qualitative methods and analysis to allow for an in-depth and rich evaluation of the complexities underscoring FE digitalisation in a previously unexplored context. Between 2017 and 2019, in-depth interviews with 18 foundational SMEs ( $\mathrm{n}=2$ providential, $\mathrm{n}=10$ material, $\mathrm{n}=6$ overlooked) distributed across Wales were employed (Appendix 2). Follow-up interviews were conducted with overlooked businesses to explore longitudinal developments. The interviews investigated the barriers for FE digitalisation and the socio-economic and spatial consequences, following a semi-structured interview schedule which assessed the digital infrastructure, uses of technology and digital capabilities. Additional questions related to the spatial implications of the business' DMI, including access to local networks and training. Transcribed interview data was inititally inductively analysed manually by the lead coder using a three-stage concept coding process (Saldaña, 2021). First, a series of explainations for uneven digitalisation were identified, focusing on the attributed meanings behind the participants' claims. These were then grouped based on their explanatory similarities, and finally clustered based on their overall conceputalisation of the problem. The coding sheet for this process is detailed in Appendix 3. The coding was subsequently entered into the qualitative software analysis, NVivo, where intercoder reliability checks were performed. 


\section{Findings}

\section{Stage 1: Digital Maturity and the digital divide}

Regression analysis set out in Table 2 confirms that foundational and non-foundational firms are becoming more digitally mature over the period studied, by comparing 2018 DMI to the baseline level DMI in 2017 (at 99\% significance level). However, the foundational businesses are less digitally mature compared to their non-FE counterparts (at 90\% significance level). Other characteristics of heightened digital maturity are the larger (medium sized) and urban firms (at 95\% or 99\% significance level). Therefore, while digital maturity is increasing across Welsh businesses, there remains differences with foundational, micro and small, and rural businesses remaining less digitally mature than non-foundational equivalents.

\section{[Insert Table 2]}

Our analysis includes interaction terms, which provide a difference in difference estimator helping to determine the gap in the DMI between foundational businesses and non-foundational businesses. From this analysis, we suggest that further differences are not experienced depending on whether the business is rural or urban. Moreover, the findings highlight that the DMI difference between foundational and non-foundational businesses also do not change over the time studied. This suggests that the foundational and non-foundational businesses are becoming more digitally mature at a similar rate, which is in contrast to other businesses whereby urban firms are becoming more digitally mature at a faster rate (Salemink et al., 2017). As such, an important finding is that being foundational is not exacerbating the differences in rural and urban digitalisation. Though the rural foundational businesses remain less digitally mature, the gap is not increasing.

The existence of a digital-divide is also evidenced in the summary statistics of the digital maturity of non-foundational and foundational businesses (broken down by foundational category) across DMI dimensions. The non-foundational businesses performed, on average, higher in terms of digital maturity across all dimensions, with the differences being most pronounced for 'ICT infrastructure', 'ICT capabilities' and 'Digital Use'. On average, the overlooked received the lowest DMI scores, again with the most notable differences occurring across 'ICT infrastructure', 'ICT capabilities' and 
'Digital Use' (Appendix 4). While the summary statistics only provide a guide, they are nonetheless useful for pinpointing potential barriers of digitalisation.

The findings outline that a digital-divide exists. There are signs that improvements to digitalisation happen at the same rate both for those already digitalised and the less digitalised sectors. This is the case even in rural areas, which extant research recommends digitalisation or productivity improvement is most needed (Salemink et al., 2017). Resultantly, further improvements to digitalisation might have additional benefits for those in most need, helping to reduce gaps between businesses and regions.

\section{Stage 2: Digital barriers in access and use}

Building on Stage 1, this section investigates the incumbent hurdles for digitalisation for foundational businesses and the implications this may have when overcoming spatial inequalities within a less-developed region. Analysis pinpoints three overarching themes to explain why digitalisation was difficult for foundational businesses, especially those categorised as overlooked. The themes are access to digital infrastructure and resources; human capital, digital skills and digital engagement; and supply chain digitalisation (Appendix 3). Based on this analysis, potential spatial impacts of foundational businesses being digitally restricted in their local economies was considered.

\section{Access to digital infrastructure and digital tools}

Implementing and maintaining digital technologies was considered a substantial financial investment, especially when businesses are starting from lower digital maturity. Costs include a range of installation, broadband, hardware, software and licensing commitments. The main concerns detailed by participants were in relation to access to the digital technologies, which came with upfront and ongoing financial commitments. As one business explained:

I would say it's close to $£ 50,000$, which is a big sum of money and that's an annual renewal that we're paying at different times. (P\#10)

For this SME, this financial commitment was considered essential because of regulatory and industry demands, whereby digitalisation was mandatory for many Welsh public 
sector construction procurements. For the overlooked businesses interviewed, digitalisation was not necessarily a regulatory requirement, but a competitive one. While the advantages of implementing incremental digital advancements were frequently discussed, expensive routes were considered largely unfeasible.

Similar cost barriers were outlined by businesses across Wales, however, some additional connectivity challenges were noted by rural businesses. Although the Welsh Government's superfast broadband rollout was considered helpful for many, a small number discussed a sense of being "left behind" as "the rest of the world is moving on" (P\#2). The differences in connectivity were most notable in relation to mobile connections, which prevented some businesses from adopting digital business models where they relied on working outside of the office. While some spatial restrictions remained, predominant challenges related to the limited resources available to invest in digitalisation, especially when it was not a requisite for everyday operations.

Despite these barriers, providential and material businesses were beginning to implement additional digital technologies. This included altering customer interaction management, using video communications and social media. Additionally, all businesses regularly utilised their website, including for sales, and increasingly accessed cloud-based data sharing and retrieval that supported collaborative project development and remote working. Numerous back-of-house business processes were digitalised, such as accounting, banking, payroll, and the automation of invoices and correspondence. However, overlooked businesses utilised fewer digital tools, especially those in retail and hospitality. Where incremental digital implementations were made it was often to provide customer value, for example, the provision of broadband for hotel guests with less emphasis on altering back-office business operations.

\section{Human capital, digital skills and digital engagement}

Many overlooked foundational businesses interviewed performed the bulk of operational business activities offline, often in customer-facing roles, therefore digital skill development was not previously considered a priority. As such, a digital skills gap emerged, with participants discussing their concerns in relation to the training, time and resources needed to overcome these hurdles. Foundational businesses from across the three categories expressed concern that to successfully implement digital advancements 
ongoing training and skill development would be required, with further commitment of time and resource Therefore, implementing digital advancements, even when incremental, was considered difficult without substantial training, ongoing support and a designated ICT specialist to guide required changes.

While human capital emerged as a barrier, overcoming these challenges was also restricted by the FE's cultural and structural characteristics. Participants noted that longterm commitment and gradual implementation was required. Furthermore, generational differences were observed. Many foundational businesses interviewed were owned and operated by individuals or families over a long period of time. There were concerns about trust, security and developing sufficient skillsets to be able to compete with upcoming generations:

It would be very useful to us older people to feel confident that we're secure in what we're doing ... The younger people are much savvier, having had computers at school, to be able to do these things without thinking. For older people, we need to think before we do anything. (P\#18)

The Welsh Government has attempted to alleviate such concerns, providing funding, digital training and mentoring. However, foundational businesses discussed their concern that short-term training and periodic mentorship could not overcome differences in capacities or provide the confidence needed to alter traditional business activities. Moreover, those particularly in need of the training were further restricted by their reduced capacity to travel to training locations. Again, the barrier existed across the Welsh businesses studied, though the situation was exacerbated for those in remote locations where distances to training providers were sizeable. In particular, the concerns were most prevalent for overlooked businesses.

The construction businesses offer useful insight into cultural hurdles, especially in family-run SMEs. The participants discussed their workers being "very scared of technology" (P\#11). Yet, motivation to digitalise was noted as businesses were passed onto the next-in-line, with a greater push for gradual digitalisation, increased training support and provision of digital technologies. Again, the challenges were similar for 
businesses located across Wales, relating to the FE businesses' structural and cultural characteristics.

Online training was not considered a redress, with participants discussing the need for existing digital competence, as well as these options failing to address cultural hurdles. Moreover, accessing support from other, more digitalised, sectors was not considered feasible. A similar challenge was the difference in access to collaborative sectoral and cross-sector digital support, training and knowledge sharing. The foundational businesses were largely unaware if these digital platforms existed. Instead, the foundational businesses looked to offline methods to provide digital support in-house. For example, construction businesses observed the benefit of pairing less digitally skilled staff with tacit on-site knowledge with less experienced employees with greater technical skillsets.

\section{Supply chain digitalisation}

The extent of digitalisation along businesses' supply chains presented a further challenge. While businesses were able to implement front-of-house digital adoptions, to alter business-to-business operations a level of digital maturity was required for the producers, suppliers and distributers. Construction businesses were particularly concerned about these restrictions:

\footnotetext{
A lot of our contractors are very old-school. Some of them are even handwriting their invoices, and you can't read what they've written. I don't know how they can operate. There are still a lot like that. There are a lot of one-man bands. They're never going to change; they've done it since they started, so why would they bother? (P\#9)
}

Even where businesses have the capacity to implement digital advancements, they remain restricted by supply chains with other foundational businesses, where hurdles of finance and human capital persist. Therefore, while the supply chain might be local, it was not possible to easily amend and digitalise business-to-business operations. Similarly, for the overlooked businesses the supply chains were often relatively small and relied on longlasting face-to-face or telephone interactions, which could not easily be adapted digitally.

\section{Discussion}




\section{Digitalisation as an opportunity or a divide for the FE in less-developed regions?}

This study provides a multifaceted exploration of foundational SMEs' digitalisation in Wales, examining the complexities behind digitalisation (Bailey and de Propris, 2020; Barzotto et al., 2020). While the grey literature and conceptual commentaries have noted the digitalisation barriers for foundational businesses (Barbera and Jones, 2020; Kiron et al., 2016), we have presented empirical evidence that a digital-divide exists between foundational and non-foundational businesses. Moreover, we extend existing studies by granting focus to the overlooked category, which despite its potential importance as a stabiliser within less-developed regions (Engelen et al., 2017), remains the least digitally mature and experiences the most cumbersome challenges to digitalisation.

Given the composition of the foundational sectors it is perhaps unsurprising that foundational SMEs are digitally less mature, using fewer digital tools in their everyday business activities and when interacting with their supply chains, consumers and networks. However, the findings suggest that even when there are intentions to digitalise, the sectoral, structural and, to a lesser extent, spatial barriers create long-term hurdles. Starting from a lower digital maturity base, the SMEs require substantial financial and time commitments to implement digital technologies and train their workforce. These costs are often long-term, requiring subscriptions, licenses and ongoing investment. For the material and providential businesses, there was greater uptake driven in part by access to more resources, but also increasing regulatory and competitive pressures. However, for overlooked businesses digitalisation was implemented to the extent needed to respond to customer demand, rather than altering business activities. More problematic is the human capital and cultural barriers that disrupt digitalisation, with foundational workers struggling to access necessary training, networks and resources to feel confident in using digital tools (Kiron et al., 2016). Moreover, even if foundational SMEs can overcome the first two hurdles, digitalisation can be prevented by the extent of digital maturity, resources and workers' skillsets across the supply chains, further removing the foundational businesses and workers from advancements accessible to other nonfoundational businesses.

However, from these findings there is some scope for optimism, since difference in difference estimators suggest that the gap is not worsened by locality, for example, the difference in digital maturity is consistent between the gap between non- 
foundational businesses across urban and rural localities. This contrasts with established evidence that rural areas tend to be slower to adopt broadband and digital technologies (Salemink et al., 2017; Townsend et al., 2013) Thus, while foundational and rural businesses are less digitally mature when considered separately, the divide is not further exacerbated by being foundational and positioning in urban and rural regions. This leads us to the next point of examination, as to whether focusing on digitalisation of the FE can help to support regional inequalities, especially if targeted to less-developed regions. These findings remind us that less-developed regions are not homogenous socio-economic spaces, but variated spatial landscapes of cities and wider regions, urban and rural spaces. While the FE businesses are similarly found across this landscape, the uneven nature of digital maturity in such organisations points to the challenges faced in harnessing foundational sectors in support of regional development. Indeed, while the experimentalist approach put forward by researchers (Barbera and Rees Jones, 2020) may help to identify innovative responses to the challenges of FE in less-developed regions, this paper suggest that it will be important to complement such prescriptions with efforts to address gaps in digital infrastructure and support for digital maturity across its sectors.

\section{Digital (dis)engagement and digital (dis)embeddedness}

Central to inclusive growth is the promotion of "spatially and socially more balanced development" (Deas et al., 2020: 7). We suggest that this should also include digital developments that can provide the spatial and social outcomes needed for businesses, in order to better support struggling communities and workers. Stage 1 provides some optimism, in that digitalisation is affected by foundational status and region, but not exacerbated when the two combine. However, the interview analysis suggests that spatial barriers interact with the business (access to finance and resources), sectoral (culture and industry practices) and structural (age of workforce) challenges. While many of the challenges existed for all businesses studied, additional hurdles were present for rural businesses, including infrastructure limitations. In all cases, the complexities were heightened for overlooked businesses in a less-developed regional context. Overall, we suggest that foundational businesses are experiencing digital dissonance, whereby discord emerges between the potential benefits of digitalisation and the lived-reality of 
foundational businesses. This dissonance is underscored with tensions about the pace of change and a concern about being left-behind digitally.

From these findings we suggest that foundational SMEs, in particular those in the overlooked category, are becoming digitally disengaged and even disembedded from local foundational and non-foundational businesses, networks and supply chains. This potentially limits their potential to engage in the wider digital economy and benefit from the efficiencies offered through digital service delivery to a wider community of residents. Though the barriers exist online, we propose that they manifest into offline challenges that can reduce the gains from local and regional embeddedness (Thompson et al., 2020). Stage 2 details three overarching challenges for foundational businesses when attempting to digitalise aspects of their operations. Combined these demonstrate reduced digital engagement and online collaborations between foundational businesses or across foundational and non-foundational barriers. Gaps in human capital, training opportunities and access to support networks slows down the potential rate of digitalisation. Where advancements are made, the pace of transition is reduced by other businesses' digital maturity. Network embeddedness relies on access to activities in the local supply networks, the ongoing building of trust and connections, and sharing of tacit knowledge (Barzotto et al., 2020; Thompson et al., 2020). Increasingly, these offline processes are being imbrued with online versions (Shemi and Procter, 2018), which the FE is struggling to access. Moreover, recent studies outline the potential enabling role of digitalisation in embedding similar workers and businesses around interpersonal networks of trust (Wood et al., 2019), and high-tech businesses are able to maximise from embedding in their sectoral, local and global regimes (Quinones et al., 2020). In lessdeveloped regions such challenges can provide an opportunity to strengthen the economy and an alternative dominant narratives around high-tech and high growth in policy prescriptions (Morgan, 2109). Therefore, we suggest that these barriers require academic and policy attention, since leaving them unaddressed creates a potential to widen inequalities (Bailey and de Propris, 2019) and de-stabilise foundational activities (Barzotto et al., 2020; Thompson et al., 2020) as other industries further embed their training, relational and supply activities online. 


\section{Conclusion}

The FE is emerging as an important academic and policy domain, yet research remains nascent (Froud et al., 2020; Nygaard and Hansen, 2020). This study makes a number of contributions. First, we demonstrate that a digital-divide exists between foundational and non-foundational businesses, and across FE's categories. The bulk of the extant literature assesses the providential and material categories, this study shows that the overlooked category is falling behind in terms of their digitalisation and recognition within the FE debate. These disadvantages exist despite these sectors offering the potential to doubleup as accelerators of regional development, as well as stabilisers of regions, thus supporting the tenets of inclusive growth. Refocusing support for foundational businesses may benefit policy initiatives around inclusive growth.

The second contribution is the potential regional implications of the digital-divide for less-developed regions. Foundational businesses are not restricted by their geography and offer a potential route to narrowing both intra and inter regional inequalities and supporting the development of embedded and resilient regional economies (De Boeck et al., 2019; Thompson et al. 2020). While the literature points to the stabilising ability of grounded firms (Engelen et al., 2017), little has been done to investigate how digital hurdles can be a source of destabilisation. Drawing on theories of network and normative embeddedness, we question the extent inclusive and sustainable regional economic gains (normative) can be made when foundational businesses are being excluded from the local networks, relationships, and collaborations that encourage the sharing of tacit knowledge and trust (network). While digital barriers occurred online, we suggest that overtime they may have increasing offline implications, especially as overcoming digital dissonance and disengagement is a long-term and complex endeavour. As such, sectoral-based restrictions offer the potential for spatial and policy implications.

As multi-level governance structures increasingly apply principles of inclusive growth, more is needed to consider how digital-divides can impede these pursuits in a less-developed region. Long-term investment in overcoming digital hurdles is already underway (Feijóo et al., 2018), with heightened recognition that change needs to be gradual and supportive of foundational activities. Our research points to an opportunity to complement existing experimental FE approaches, by targeting support around a twin 
focus of redressing uneven digital capabilities within FE firms and ensuring such businesses are able to catch-up with their non-foundational counterparts.

Further targeting of government resources and training towards rural foundational businesses may also help to relieve some existing spatial divides, as these businesses may benefit further from the socioeconomic outcomes aligned to digitalisation (Hansen, 2021). These findings suggest that while FE has potential to aid regional development through the offer of new services and improved efficiency, it is unlikely to do so 'equally' without attention to its digitalisation. In this respect greater investment in digital technologies might present opportunities for FE services to reach more parts of the region and connect with citizens locally and regionally. This may help it to respond to the growing provision of services digitally, further enhanced during the coronavirus pandemic where greater attention needs to be granted to local consumption and production (Bassens et al., 2020). More broadly, it is important to support the regional economy and enhance labour market participation through education, training, and skills policy.

This study is not without its limitations. The findings are based on a case study of Wales where policy supports foundational principles, future studies could extend the scope to sites where agglomeration and market exchange policies are prevalent. Our focus is primarily on the capability and capacity of the FE to operate as a place-based policy capable of bringing about socio-economic outcomes for a lagging region. We point to the processes and barriers for the FE and what it might mean for their embeddedness. Further research could build upon our findings and measure the wider regional economic developments effects coming from the (dis)engagement and (dis)embeddedness. Moreover, rather than focusing on the opportunities and threats for SMEs, there could be a deeper analysis of the employment effects for workers in micro, medium and large enterprises. Also, studies could focus on FE's offline embeddedness, examining whether it requires digital support or the extent it is impacted by businesses' digitalisation. Moreover, studies have expressed doubt about applying metrics that rely on productivity or efficiency as a means to measure foundational outputs (Froud et al., 2019; Engelen et al., 2017), however, there has been minimal focus about the complementarity of foundational business support with socioeconomic outputs. We begin to demonstrate these benefits, which follow-up research could further examine. 


\section{References}

Arcidiacono D and Pais I. (2020). Re-embedding the Economy within Digitalized Foundational Sectors: The Case of Platform Cooperativism. In: Barbera F and Jones IR (eds) The Foundational Economy and Citizenship: Comparative Perspectives on Civil Repair. Bristol University Press, pp.27-50.

Arntz M, Gregory T and Zierahn U. (2016). The Risk of Automation for Jobs in OECD Countries, Paris: OECD Publishing.

Bailey, D. and De Propris, L. (2019). Industry 4.0, Regional Disparities and Transformative Industrial Policy, Regional Studies Policy Impact Books, 1(2), pp.67-78.

Barbera F. and Rees Jones I. (2020). The foundational economy and citizenship: Comparative perspectives on civil repair. Policy Press: Bristol.

Barzotto, M., Corradini, C., Fai, F., Labory, S. and Tomlinson, P.R. (2020). Smart specialisation, Industry 4.0 and lagging regions: some directions for policy. Regional Studies, Regional Science, 7(1), pp.318-332.

Bassens, D., Kębłowski, W. and Lambert, D. (2020). Placing cities in the circular economy: neoliberal urbanism or spaces of socio-ecological transition?. Urban Geography, 41(6), pp.1-5.

Bearson D, Kenney M and Zysman J. (2021). Measuring the impacts of labor in the platform economy: new work created, old work reorganized, and value creation reconfigured. Industrial and Corporate Change, 30(3), pp.536-563

Belzunegui-Eraso A. and Erro-Garcés A. (2020). Teleworking in the context of the covid19 crisis, Sustainability 12(9), 3662. 
Bentham J, Bowman A, de la Cuesta M, et al. (2013) Manifesto for the foundational economy. Manchester: Centre for Research on Socio-Cultural Change.

Birch K., Mackinnon D. and Cumbers A. (2010). Old industrial regions in Europe: A comparative assessment of economic performance, Regional Studies 44(1), pp.35-53.

Brill, L., Cowie, L., Folkman, P., Froud, J., Johal, S., Leaver, A., Moran, M. and Williams, K., (2015). What Wales Could Be. CRESC Report for FSB Wales, Manchester. Retrieved: https://www.research.manchester.ac.uk/portal/en/publications/what-walescould-be(0b8f81d5-4dd3-495c-928e-f6aa2fa351da).html

Coenen L., Moodysson J. and Martin H. (2015). Path renewal in old industrial regions: Possibilities and limitations for regional innovation policy, Regional Studies, 49(5), pp.850-65.

Deas, I., Haughton, G. and Ward, K., (2020). Scalar postpolitics, inclusive growth and inclusive economies: challenging the Greater Manchester agglomeration model. Cambridge Journal of Regions, Economy and Society. https://doi.org.uk/10.1093/cjres/rsaa022

De Boeck, S., Bassens, D. and Ryckewaert, M., (2019). Making space for a more foundational economy: The case of the construction sector in Brussels. Geoforum, 105, pp.67-77.

Engelen E., Froud J., Johal S., Salento A. and Williams K. (2017). The grounded city: From competitivity to the foundational economy, Cambridge Journal of Regions, Economy and Society, 10(3), pp.407-23.

Eurostat. (2008). NACE Rev.2: statistical classification of economic activities in the European Community. Eurostat. Retrieved: https://ec.europa.eu/eurostat/documents/3859598/5902521/KS-RA-07-015EN.PDF/dd5443f5-b886-40e4-920d-9df03590ff91 
Estela, O. (2019). The Foundational Economy and strategic planning in Barcelona: reshaping the urban economy from the bottom up. Renewal: a Journal of Labour Politics, 27(2), pp.33-39.

Feijóo C., Ramos S., Armuña C., Arenal A. and Gómez-Barroso J.-L. (2018). A study on the deployment of high-speed broadband networks in NUTS3 regions within the framework of digital agenda for Europe, Telecommunications Policy, 42(9), pp.682-99.

Feldman M, Guy F and Iammarino S. (2021). Regional income disparities, monopoly and finance. Cambridge Journal of Regions, Economy and Society, 14(1), pp.25-49.

Foundational Economy Collective. (2020). Activity Classification. Foundational Economy Collective. Retrieved: https://foundationaleconomy.com/activityclassification/ [Accessed:12/11/2020]

Froud J., Haslam C, Johal S., Williams, K. (2020). (How) does productivity matter in the foundational economy? Local Economy, 35(4), pp.316-336.

Graham M., Hale S. and Stephens M. (2012). Featured graphic: Digital divide: The geography of internet access, Environment and Planning A: Economy and Space, 44(5), pp.1009-10.

Green, A., Parke, C., Hoole, C. and Sevinc, D. (2021). Unlocking inclusive growth by linking micro assets to anchor institutions: The case of skilled overseas migrants and refugees and hospital jobs. European Urban and Regional Studies, pp.1-16.

Grubesic T. H. and Mack E. A. (2016). Broadband telecommunications and regional development. Routledge, Abingdon: Oxon.

Hansen T. (2021) The foundational economy and regional development. Regional Studies, pp.1-10. 
Hassink, R. (2020). Advancing place-based regional innovation policies. Regions and Innovation Policies in Europe. Edward Elgar Publishing.

Henderson, D., Jones, C., Munday, M., Norris, L., Reynolds, L., Roberts, A., Roche, N. and $\mathrm{Xu}, \mathrm{C} .22020$. Digital maturity economic impact report 2019. Retrieved from: https://orca.cardiff.ac.uk/133568/1/DMEIR\%202019-full-report.pdf $\quad$ [Accessed: $01 / 12 / 2021]$

Henley A. and Lang M. (2017). Self-employment in Wales: Micro-business activity or the rise of the gig economy?, Welsh Economic Review 25, pp.9-17.

Institute of Welsh Affairs. (2020). It's time to focus on the everyday economy. Institute of Welsh Affairs. Retrieved: https://www.iwa.wales/agenda/2020/01/its-time-to-focuson-the-everyday-economy/ [Accessed:12/11/2020]

Johal, S., Moran, M. and Williams, K., (2017). Avoiding 'back to the future' policies by reforming the 'foundational economy'. In: Jones, B. O'Donnell, M. eds. Alternatives to Neoliberalism: Towards Equality and Democracy, pp.175-192.

Jones C. and Henderson D. (2019). Broadband and uneven spatial development: The case of Cardiff city-region, Local Economy, 34(3), pp.228-47.

Jones, R., Goodwin-Hawkins, B. and Woods, M., (2020). From Territorial Cohesion to Regional Spatial Justice: The Well-Being of Future Generations Act in Wales. International Journal of Urban and Regional Research, 44(5), pp.894-912.

Kiron, D., Kane, G.C., Palmer, D., Phillips, A.N. and Buckley, N., (2016). Aligning the organization for its digital future. MIT Sloan Management Review, Deloitte University Press: Texas. Retrieved:

http://www.enterprisesolutions.tsg.com/sites/default/files/Deloitte\%20\%20Aligning\%20the\%200rganization\%20for\%20Its\%20Digital\%20Future.pdf 
Kenney M and Zysman J. (2016) The rise of the platform economy. Issues in Science and Technology 32: 61.

Leaver, A. and Williams, K. (2014). After the 30-year experiment: The future of the foundational economy. Juncture 21(3), pp.215-221.

Lee, N. (2019). Inclusive Growth in cities: a sympathetic critique. Regional Studies, 53(3), pp.424-434.

Lee, N. and Sissons, P. (2016). Inclusive growth? The relationship between economic growth and poverty in British cities. Environment and Planning A: Economy and Space, 48(11), pp.2317-2339.

Mack E. A. (2014). Broadband and knowledge intensive firm clusters: Essential link or auxiliary connection?, Papers in Regional Science, 93(1), pp.3-29.

Mason C., Brown R., Hart M. and Anyadike-Danes M. (2015). High growth firms, jobs and peripheral regions: The case of Scotland, Cambridge Journal of Regions, Economy and Society, 8(2), pp.343-58.

Miles, J. (2017). Keynote speech on the Foundational economy. Jeremy Miles. Retrieved: http://www.jeremymiles.cymru/en/keynote-speech-on-the-foundational-economy/

Morgan, K. (2019). The future of place-based innovation policy (as if 'lagging regions' really mattered). Regional Studies Policy Impact Books, 1(2), pp.79-89.

Morgan, K. (2020). After the Pandemic: societal innovation and the foundational economy. Orkestra. Retrieved: https://www.orkestra.deusto.es/en/latest-news/newsevents/beyondcompetitiveness/1986-after-the-pandemic-societal-innovation-and-thefoundational-economy [Accessed 06/11/2020] 
Norris L. (2020). The spatial implications of rural business digitalization: Case studies from Wales. Regional Studies, Regional Science, 7(1), pp.499-510.

Nygaard B and Hansen T. (2020). Local development through the foundational economy? Priority-setting in Danish municipalities. Local Economy 35, 768-786.

OECD. (2019). Vectors of digital transformation. OECD iLibrary. OECD. Retrieved https://www.oecd-ilibrary.org/content/paper/5ade2bba-en [Accessed: 02/06/2020]

Pike, A., Rodríguez-Pose, A. and Tomaney, J., (2017). Shifting horizons in local and regional development. Regional Studies, 51(1), pp.46-57.

Pugh, R., MacKenzie, N. G., and Jones-Evans, D. (2018). From 'techniums' to 'emptiums': The failure of a flagship innovation policy in Wales. Regional Studies, 52(7), pp.1009-1020.

Quinones, G., Heeks, R. and Nicholson, B., (2020). Embeddedness of digital start-ups in development contexts: field experience from Latin America. Information Technology for Development, pp.1-20.

Saldaña, J., 2021. The coding manual for qualitative researchers. Sage: London.

Salemink K., Strijker D. and Bosworth G. (2017). Rural development in the digital age: A systematic literature review on unequal ICT availability, adoption, and use in rural areas, Journal of Rural Studies, 54, pp.360-71.

Shemi, A.P. and Procter, C. (2018). E-commerce and entrepreneurship in SMEs: case of myBot. Journal of Small Business and Enterprise Development, 25(3), pp.501-520.

Thompson, M., Nowak, V., Southern, A., Davies, J. and Furmedge, P., (2020). Regrounding the city with Polanyi: From urban entrepreneurialism to entrepreneurial municipalism. Environment and Planning A: Economy and Space, 52(6), pp.1171-1194. 
Townsend L., Sathiaseelan A., Fairhurst G. and Wallace C. (2013). Enhanced broadband access as a solution to the social and economic problems of the rural digital divide, Local Economy, 28(6), pp.580-95.

Tranos, E. and Gillespie, A. (2009). The Spatial Distribution of Internet Backbone Networks in Europe: A Metropolitan Knowledge Economy Perspective, European Urban and Regional Studies, 16(4), pp. 423-437.

Tranos E. and Mack E. A. (2015). Broadband provision and knowledge-intensive firms: A causal relationship?, Regional Studies, 50(7), pp.1113-26.

Tranos E., Kitsos T. and Ortega-Argilés R. (2020). Digital economy in the UK: Regional productivity effects of early adoption, Regional Studies, pp.1-15.

Tranos E. and Nijkamp P. (2013). The death of distance revisited: Cyber-place, physical and relational proximities, Journal of Regional Science, 53(5), pp.855-73.

Trippl M. and Otto A. (2009) How to turn the fate of old industrial areas: A comparison of cluster-based renewal processes in Styria and the Saarland, Environment and Planning A: Economy and Space, 41(5), pp.1217-33.

White, M. C. (2004). Inward Investment, Firm Embeddedness and Place: An Assessment of Ireland's Multinational Software Sector, European Urban and Regional Studies, 11(3), pp. 243-260.

Wood, A.J., Graham, M., Lehdonvirta, V. and Hjorth, I., (2019). Networked but commodified: The (dis)embeddedness of digital labour in the gig economy. Sociology, 53(5), pp.931-950. 
